\title{
Ensino Colaborativo e Inclusivo: Políticas e Práticas de Inclusão Usando Tecnologias
}

\author{
Inclusive and Collaborative Teaching: \\ Policies and Practices of Inclusion Using \\ Technologies
}

\author{
Naiara Chierici da Rocha \\ Universidade Estadual Paulista
}

Elisa Tomoe Moriya Schlünzen

Universidade Estadual Paulista

\section{Danielle A. Nascimento dos Santos}

Universidade Estadual Paulista

\begin{abstract}
Resumo: $O$ presente artigo tem por objetivo apresentar reflexões acerca das políticas públicas de inclusão que trazem nuances do ensino colaborativo entre os professores da Educação Especial e os professores do ensino regular, no contexto escolar do estado de São Paulo. Para isso, destacam-se as concepções de um ensino colaborativo para uma escola inclusiva, junto às diretrizes das políticas públicas. Além dessas reflexões, são discutidas percepções das práticas observadas em uma escola estadual do município de Presidente Prudente/SP entre uma professora da Educação Especial e uma professora de Matemática. Apresenta-se junto a essas reflexões a concepção da abordagem Construcionista, Contextualizada e Significativa (CCS) como potencializadora para práticas inclusivas e colaborativas por meio das Tecnologias. A partir disso, foi possível refletir sobre a necessidade de efetivação das políticas públicas em relação ao ensino colaborativo, considerando as especificidades e necessidades das escolas e do trabalho pedagógico dos professores
\end{abstract}

Palavras-chave:Ensino Colaborativo. Educação Especial. Inclusão. Políticas Públicas

\begin{abstract}
This paper aims to present reflections on public policies of inclusion that bring nuances of collaborative teaching among Special Education teachers and regular education teachers in the school context of the state of São Paulo. For this, there is the conceptions of a collaborative teaching for an inclusive school with guidelines of public policies. Along with these reflections, the study looked at for teaching practices used in a school in Presidente Prudente/SP. It was noted the work between a teacher of Special Education and a mathematics teacher. It is presented together with these reflections the design of the Constructionist, Contextualized and Meaningful Approach(CCS) as potentiator for inclusive and collaborative practices through technology. Therefore, it was possible to reflect about the effective public policies requirements in relation to collaborative education, considering the school and educational work specificities and necessities..
\end{abstract}

Keywords:Collaborative Education. Special Education. Inclusion. Public Policies.

ROCHA, Naiara Chierici; SCHLÜZEN, Elisa Tomoe Morya; SANTOS, Daniele A. Nascimento. Ensino Colaborativo e Inclusivo: políticas e práticas de inclusão usando tecnologias. Informática na Educação: teoria \& prática, Porto Alegre, v. 19, n. 3, p. 129-144, set./dez. 2016. 


\section{Introdução}

As políticas públicas devem se configurar nos resultados de um debate e construção coletiva que represente os anseios da sociedade. Dessa forma, vê-se política conforme Jenkins (1978 apud DAGNINO, 2002) como um "conjunto de decisões inter-relacionadas, concernindo à seleção de metas e aos meios para alcançá-las, dentro de uma situação especificada".

Nesse direcionamento, entende-se que nas últimas décadas as políticas públicas em educação têm acenado e alterado de forma significativa a educação básica para os princípios de uma educação igualitária e para todos. No que tange às pessoas com deficiência, as políticas públicas têm fundamentado as tomadas de decisões e legitimado o direito das pessoas com deficiência à educação básica.

No Brasil, foi a partir da década de 1990 que os debates sobre os direitos das pessoas com deficiência tomaram maior destaque. Com enfoque para o discurso de uma educação de qualidade para todos, a legislação nacional tomou como base algumas diretrizes de documentos internacionais, proporcionando assim um novo cenário para a Educação Especial e para a educação inclusiva no Brasil.

No entanto, foi a partir dos anos 2000 que a Educação Especial no Brasil passou a ter novas configurações em termos legais. A partir dessa década, a Educação Especial passou a ter um importante papel no âmbito da educação inclusiva, pois foi a partir dela que a educação inclusiva tem se estabelecido no cenário educacional brasileiro.

Destaca-se, a partir de Prieto (2010, p.61), que a Educação Especial ao longo dos anos passou a "um tratamento no campo da legislação e política nacional que nos permite afirmar a existência de um movimento na direção de the atribuir um significado diferenciado dos anos anteriores". Esse fato é importante, já que, a partir desse novo significado que importantes documentos foram reorganizados e reestruturados no cenário educacional para compor um novo quadro e tomada de decisões para a educação inclusiva.

Assim, a partir das reformulações das políticas públicas que versam sobre a Educação e em particular a educação inclusiva, tem-se que "na perspectiva da educação inclusiva, a Educação Especial é definida como uma modalidade de ensino transversal a todos os níveis, etapas e modalidades" (BRASIL, 2008, p.3).

O Atendimento Educacional Especializado (AEE) é fruto das mudanças históricas e políticas da Educação Especial no Brasil numa perspectiva inclusiva. Sendo assim, junto com a política do AEE e suas demandas tem-se, a especificidade do trabalho e formação de professores, a organização e gestão da escola para a inclusão escolar. Nessa perspectiva de atendimento, tem-se uma nova proposição política que se sustenta em três eixos: gestão, formação de professores e inclusão escolar. Esses eixos articulados entre si configuram a escola sob nova organização (MICHELS, 2009).

Com base nessa nova organização apontada por Michels, (2009) é que surge a necessidade de se pensar a educação inclusiva com base nos princípios de um ensino colaborativo, dado o processo histórico e marcos legais que atribuíram um novo sentido da Educação Especial numa perspectiva inclusiva. 
É pautado nos princípios da Educação Especial na perspectiva de educação inclusiva que se tem como objetivo do presente artigo apresentar reflexões acerca das políticas públicas de inclusão que trazem nuances do ensino colaborativo entre a Educação Especial, junto ao ensino regular. Para isso, as reflexões serão pautadas especificamente para o trabalho pedagógico dos professores da Educação Especial e os professores do ensino regular, no contexto do estado de São Paulo.

Buscar-se-á dar destaque às principais políticas públicas atuais que contribuem para um trabalho articulado entre a Educação Especial e a educação regular, pontuando a forma como as políticas trazem essas questões, fragilidades e desafios que marcam a proposta de um ensino colaborativo.

Para isso, este artigo se divide em dois momentos: o primeiro busca esclarecer o que se entende por ensino colaborativo para uma escola inclusiva, apresentar as políticas públicas de inclusão que trazem nuances sobre essa perspectiva e de que forma isso é compreendido.

O segundo momento se pauta nas reflexões a partir das principais percepções das práticas observadas em uma escola estadual do município de Presidente Prudente/SP. Destaca-se que essas percepções foram extraídas dos registros de observações de uma pesquisa de Mestrado (em andamento) . Nessas reflexões são consideradas a importância do ensino colaborativo para a educação inclusiva, destacando as percepções de uma realidade em que se contrasta as diretrizes das políticas públicas, e as parcerias entre a Educação Especial e o ensino regular.

Apresenta-se também reflexões sobre o uso das Tecnologias Digitais de Informação e Comunicação (TDIC) como potencializadora de práticas inclusivas a partir da abordagem Construcionista, Contextualizada e Significativa (CCS) como apoio ao ensino colaborativo.

Desse modo, foram utilizadas para fomentar as discussões, a Política Nacional de Educação Especial na Perspectiva da Educação Inclusiva (2008) e resoluções estaduais que dispõe sobre a Educação Especial nas unidades escolares da rede estadual de ensino. As reflexões serão centradas sob o ponto de vista da Educação Especial, seus serviços atuais prestados para o ensino regular e a proposta de um trabalho colaborativo e articulado entre os agentes escolares, principalmente os professores que atuam com os estudantes Público Alvo da Educação Especial (PAEE) .

\section{Ensino Colaborativo e Políticas Públicas para uma escola inclusiva}

As reflexões que serão realizadas nesse tópico remetem a indagações de como vem ocorrendo os processos de inclusão escolar. Há articulação entre os professores do ensino comum e educação especial? Como vem sendo desenvolvido o trabalho pedagógico desses professores em contextos reais de acordo com as políticas públicas? Quais são as condições de trabalho existentes para que essas premissas ocorram?

As políticas públicas, têm apresentado diretrizes em busca de estratégias que visam garantir a permanência, efetivação e aprendizagem significativa para todos no contexto escolar. Sob a responsabilidade de pensar a inclusão escolar dos estudantes PAEE, é que surge a necessidade de refletir a concepção de ensino colaborativo para as práticas pedagógicas e, principalmente, os direcionamentos que as políticas públicas trazem. 
Diante dessa perspectiva, entende-se que o ensino colaborativo no âmbito da Educação Especial e regular parte do princípio da existência de uma parceria entre os professores do ensino regular e da Educação Especial. Essa parceria e colaboração se configuram como uma estratégia e corresponsabilidade para articular os serviços da Educação Especial com o ensino regular almejando favorecer a aprendizagem dos estudantes PAEE considerando o mesmo currículo para todos.

Mendes, Vilaronga e Zerbato (2014) destacam que o ensino colaborativo é um modelo de prestação de serviço de apoio no qual um professor do ensino regular e um professor especializado dividem a responsabilidade de planejar, instruir e avaliar o ensino dos PAEE na sala de aula comum.

O termo "ensino colaborativo" é definido como uma parceria entre os professores do ensino regular e especial. Cook e Friend (1995) reforçam a ideia de que essa parceria ocorre desde que os dois professores se responsabilizem e compartilhem com o planejamento até a avaliação das atividades escolares na sala de aula comum, pensando os PAEE junto aos demais estudantes.

Concorda-se com Cook e Friend (1995), ao esclarecerem que trabalhar colaborativamente é exercer um trabalho com parcerias para um bem comum, no desenvolvimento de um ensino mais adequado para se potencializar a aprendizagem e socialização do PAEE.

Essa parceria é fundamental para propiciar melhor planejamento, avaliação e organização de recursos de ensino para os estudantes Público Alvo da Educação Especial (PAEE). A partir dessa concepção, destaca-se, segundo Silva (2007), que essa troca se torna possível e eficiente, uma vez que os professores regulares são especialistas em conteúdo específicos de uma determinada disciplina escolar, e os professores da educação especial são especialistas em avaliação e conteúdo específicos sobre as especificidades da educação especial.

As reflexões anteriores conduzem ao entendimento de que o ensino colaborativo consiste, além da parceria na divisão da responsabilidade, em planejar, instruir e avaliar procedimentos de ensino para todos os estudantes do ensino regular (FERREIRA, MENDES, ALMEIDA e DEL PRETTE, 2007).

Desse modo, desmistifica-se a ideia, presente ainda no interior das escolas, de que o estudante da Educação Especial é responsabilidade apenas do professor especialista que atende os estudantes PAEE. Isso contribui para compreender as diretrizes existentes na Política Nacional de Educação Especial na Perspectiva da Educação Inclusiva, assim como compreender a Educação Especial como uma modalidade transversal de ensino.

Nesse direcionamento, a proposta de ensino colaborativo, segundo Mendes (2006), surge como um modelo de prestação de serviço que visa a perspectiva inclusiva, e pressupõe mudanças nas práticas de ensino, uma vez que, é na classe comum onde todos os estudantes devem passar a maior parte do tempo de sua jornada escolar e é neste local que a inclusão de fato ocorre.

Com intuito de buscar alternativas e melhorias para o ensino dos estudantes PAEE de acordo com a Política Nacional de Educação Especial na Perspectiva Inclusiva (BRASIL, 2008), foi instituído o AEE, que deve ocorrer, prioritariamente, nas Salas de Recursos Multifuncionais 
(SRM). No entanto, o contexto em que as reflexões do presente texto se faz será sempre considerado também as especificidades do Estado de São Paulo.

De acordo com o Decreto $N^{\circ}$ 6.571, de 17 de setembro de 2008,

$\S 1^{\circ}$ Considera-se atendimento educacional especializado o conjunto de atividades, recursos de acessibilidade e pedagógicos organizados institucionalmente, prestado de forma complementar ou suplementar à formação dos alunos no ensino regular.

A partir da definição do Atendimento Educacional Especializado, atribui-se um caráter transversal e de apoio prestado pela Educação Especial. Nesse sentido, vale ressaltar e definir que, de acordo com (BRASIL, 2008, p.3), "na perspectiva da educação inclusiva, a educação especial é definida como uma modalidade de ensino transversal a todos os níveis, etapas e modalidades".

Dessa forma, a concepção de ensino colaborativo está presente na legislação, uma vez que se parte da ideia de que o ensino colaborativo é uma prestação de serviço da Educação Especial, ou seja, entende-se que o ensino colaborativo está intrínseco ao novo modelo proposto.

A proposta desse modelo pautado nas concepções do ensino colaborativo é um processo que "emergiu como uma alternativa aos modelos de sala de recursos, classes especiais ou escolas especiais, como um modo de apoiar a escolarização de estudantes com deficiência em classes comuns" (MENDES, ALMEIDA; TOYODA, 2011, p. 85).

Esse fato também pode ser destacado pela própria diretriz que a política nacional de Educação Especial faz em relação à essência das Salas de Recursos Multifuncionais (SRM). De acordo com o Ministério da Educação (MEC), as SRM são espaços da escola onde se realiza o AEE para os PAEE, por meio do desenvolvimento de estratégias de aprendizagem, centradas nas suas habilidades e potencialidades, favorecendo o acesso aos conteúdos da classe comum para a construção de conhecimentos, subsidiando-os para um desenvolvimento do currículo, participando assim da vida escolar.

Essa determinação chama a atenção para o fato de que o ensino colaborativo, segundo Machado e Almeida (2010), proporciona novos espaços e novas formas de aprendizagem, visto que possibilita apoio aos estudantes PAEE, ao trabalho pedagógico realizado e à criação de estratégias de ensino, indo ao encontro do que os marcos históricos e legais determinam como ensino inclusivo.

Nesse sentido, percebe-se a fragilidade de não se destacar com maior clareza a proposta de um ensino centrado no trabalho colaborativo. Assim, a política pouco especifica e legitima a contribuição para o planejamento e elaboração de estratégias pedagógicas inclusivas para as estudantes PAEE matriculados nos sistemas regulares de ensino. Esse fato contribui para a caracterização do AEE e dos serviços das SRM como um reforço escolar, ou apenas espaços de alfabetização sem relação com o currículo e atividades da sala comum.

O ensino colaborativo não deve ser entendido como qualquer tipo de parceria com outros profissionais que atuam em paralelo ao professor do ensino comum. Deve-se tomar cuidado para que qualquer planejamento não seja entendido como uma estratégia de ensino colaborativo numa perspectiva inclusiva. Por exemplo, separar uma sala de aula com 
estudantes com dificuldades para propor estratégias de ensino, ou remover os estudantes da sala de aula para receberem atendimento específico não se caracteriza como colaboração dentro dos princípios do ensino colaborativo para todos (CONDERMAN, BRESNAHAN E PEDERSEN, 2009a).

O que se observa em determinadas diretrizes da política nacional, também pode ser percebido nas resoluções estaduais de São Paulo. A Resolução SE no 11, de 31/01/2008, alterada pela Resolução SE no 31, de 24/03/2008 e atualizada pela Resolução SE 61, de 11-112014 dá providências correlatas sobre o atendimento dos estudantes PAEE, que estejam incluídos na classe comum e para propiciar a inclusão no sistema de ensino. Essas resoluções estabelecem a implementação do Atendimento Pedagógico Especializado (APE) com objetivo de melhorar a qualidade da oferta da Educação Especial na rede estadual e favorecendo a inclusão escolar, por meio de:

atendimento prestado por professor especializado, em sala de recursos específicos, em horários programados de acordo com as necessidades dos alunos, e, em período diverso daquele que o aluno frequenta na classe comum, da própria escola ou de outra unidade (p. 2)

Assim, tanto em âmbito nacional quanto estadual, percebe-se o caráter de apoio ao ensino regular que a educação especial e os seus serviços devem promover, visando um ensino inclusivo. No que concerne ao quadro de formação e atribuições do professor especialista, também são apresentadas diretrizes pelas políticas.

A política nacional traz indicações breves e gerais sobre a formação do professor responsável pelo $A E E$, considerando que em âmbito nacional os atendimentos não se pautam em áreas específicas da Educação Especial, diferentemente do estado de São Paulo. Isso fica claro dado que "o professor deve ter formação inicial que o habilite para o exercício da docência e a formação específica para a Educação Especial" (Art. 12). Sendo assim, essa formação específica pode ser bastante diversificada, pois considera as potencialidades de formação e os quadros existentes nos demais estados brasileiros.

Para o estado de São Paulo, a Resolução SE no 61, destaca em seu Artigo $8^{\circ}$ que

O docente que atuar no Atendimento Pedagógico Especializado - APE, sob a forma de Sala de Recursos, Itinerância ou CRPE, deverá ter formação na área da necessidade educacional especial, observada, no processo de atribuição de classes/aulas, a ordem de prioridade na classificação dos docentes, relativamente às respectivas habilitações/qualificações, de acordo com a legislação pertinente.

No que se referem às atribuições do professor especialista, a política versa sobre a possibilidade de articulação com o ensino comum.

A ação desses profissionais é pautada nas diretrizes citadas nesse artigo o Art. 13 da Política Nacional, indica que são atribuições do professor do AEE:

I - identificar, elaborar, produzir e organizar serviços, recursos pedagógicos, de acessibilidade e estratégias considerando as necessidades específicas dos alunos público-alvo da Educação Especial;

II - elaborar e executar plano de Atendimento Educacional Especializado, avaliando a funcionalidade e a aplicabilidade dos recursos pedagógicos e de acessibilidade; 


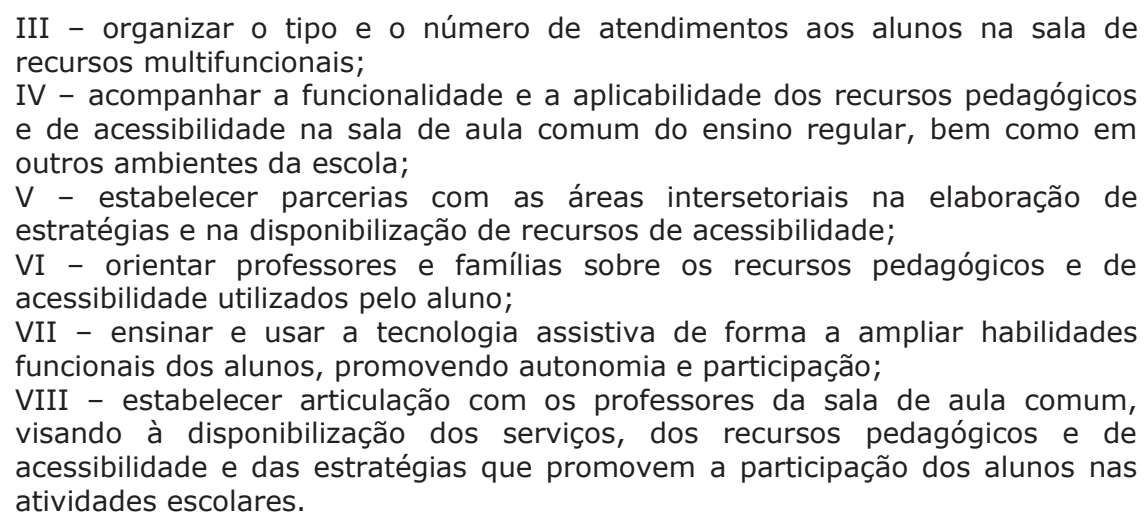

Na esfera estadual, o que chama atenção é o inciso VII do Artigo 90, por destacar e reforçar o caráter de apoio técnico-pedagógico:

VII - oferecer apoio técnico-pedagógico ao professor da classe/aulas do ensino regular, indicando os recursos pedagógicos e de acessibilidade, bem como estratégias metodológicas.

Essas atribuições, em destaque, valorizam as ações e possibilidades de práticas que são centradas nos atendimentos dos estudantes PAEE. Em relação aos incisos IV, VI e VIII da política nacional, concorda-se com Baptista (2011) que reflete para o fato de que há grande amplitude das ações desenvolvidas entre o ensino comum e a Educação Especial, mas há possibilidades interpretativas sobre as práticas de atendimento aos EPAEE. O autor, ainda esclarece que seja necessário identificar a potencial valorização do trabalho articulado com outros profissionais, principalmente com os professores do ensino comum.

No entanto, ambos os documentos deixam a critério interpretativo o que seria esse apoio ou essa articulação, uma vez que a proposta de ensino colaborativo no Brasil ainda é muito nova e pouco desenvolvida nos contextos educacionais.

Nesse sentido, seria necessário avançar no debate que associa as diretrizes da educação especial em uma perspectiva inclusiva para que haja destaque ao ensino colaborativo, que reconheça a necessidade de utilização de recursos disponíveis aliada às práticas pedagógicas inclusivas e finalmente o apoio da gestão escolar, pois o ensino colaborativo envolve ações de todos os agentes escolares.

Essas premissas de ensino colaborativo e reflexões acerca das políticas públicas atuais reforçam a importância do professor especializado em Educação Especial, posto que a Educação Especial e os seus serviços não devem substituir o ensino comum, e sim, os profissionais da Educação Especial, articulados com o ensino comum, podem promover processos e desenvolvimentos satisfatórios para os estudantes PAEE.

Assim, a perspectiva de ensino colaborativo é de paridade, tomada de decisões mutuas, sem hierarquias, professores com papel igualitário em planejar, executar e avaliar, e a valorização do conhecimento dos profissionais envolvidos (MENDES, VILARONGA e ZERBATO, 2014). Nessa vertente, Pugach e Johnson (1995) já afirmavam que a colaboração requer mudanças na visão separatista que se possui em relação aos profissionais da Educação Especial e dos professores do ensino regular, e a necessidade de se aprender com o outro. 
Dessa forma, a proposta de um ensino colaborativo implica redefinição de papéis dos professores do ensino especial como apoio e orientação centrado na classe comum. A inclusão ocorre de fato nesse espaço e não se pode apenas focar no atendimento individualizado dos EPAEE na sala de recursos, sendo que esse atendimento apenas complementa ou suplementa as atividades da sala comum.

Sendo assim, na próxima seção, é realizada uma breve análise a partir de observação em campo realizada em uma pesquisa de Mestrado que visou investigar o ensino colaborativo entre um professor especialista na área de Deficiência Intelectual e um professor de Matemática do ensino fundamental II.

\section{Percepções e práticas em uma Escola Estadual de Presidente Prudente}

As percepções relatadas neste texto se referem à observação realizada em um uma escola da rede estadual de ensino localizada no município de Presidente Prudente/SP, situada na periferia. A escola atende ensino fundamental II, Ensino médio e, compondo um quadro grande de professores, e possui coordenação a nível de ensino médio e fundamental, sendo a do ensino médio responsável pela Educação Especial.

A observação teve como principal objetivo conhecer as características do campo pesquisado, bem como compreender como eram as estratégias pedagógicas das professoras participantes da pesquisa e, mais especificamente, se havia indícios de colaboração e parceria entre ambas.

Os registros das observações ocorreram no interior da sala de aula comum e na sala de recursos, em relação aos conteúdos de Matemática com vistas a um ensino inclusivo. Os dados observados foram registrados considerando os seguintes aspectos: Conteúdo trabalho (sala comum e sala de recursos); atividades desenvolvidas; recursos e/ou estratégias utilizadas; recursos e/ou estratégias específicas para as estudantes com Deficiência Intelectual (DI); desempenho e participação das estudantes com DI e atitude das professoras envolvidas.

Sendo assim, os dados que serão apresentados foram tratados a partir da leitura sistemática e minuciosa dos registros do campo. Destaca-se que nesse artigo apresenta-se apenas uma parte dos dados coletados, uma vez que, a pesquisa de Mestrado ainda está em fase de finalização. Nesse caso, os registros observados foram transcritos e analisados a partir do referencial teórico que aborda as temáticas presentes nas ações observadas, que serão apresentados a seguir.

A pesquisa de Mestrado foi de caráter qualitativo, uma vez que, segundo Bogdan e Biklen (1994), numa pesquisa qualitativa, o pesquisador frequenta o contexto de estudo, pois se preocupa com o mesmo. Com esta pesquisa, o foco foi em relação à colaboração entre as participantes e à adoção de estratégias inclusivas que contemplassem as especificidades do contexto escolar no qual a pesquisa se desenvolveu.

As professoras participantes da pesquisa possuem as seguintes características: Professora da SR - Formação: Licenciatura em e Especialização em Educação Especial na área de Deficiência Intelectual; e Professora da sala comum de Matemática - Formação: Licenciatura em Matemática 
Pode-se observar que, quanto à formação para professor da Educação Especial, a professora participante da pesquisa segue as diretrizes estabelecidas pelas políticas públicas descritas no item 2 desse artigo.

As observações decorreram durante 5 meses de coleta de dados da pesquisa de Mestrado no ano de 2014, em que foram considerados, para o presente texto, os seguintes aspectos: características do campo a nível de atendimento nas SR, espaço físico e recursos disponíveis, práticas pedagógicas existentes e ensino colaborativo.

As observações ocorreram em uma sala de aula do sexto ano do Ensino Fundamental II. Os estudantes possuíam entre 11 e 12 anos de idade.

\subsection{Características do contexto observado}

No contexto observado há uma SR que está de acordo com o previsto nas diretrizes, com espaço amplo e com os recursos necessários para atender as especificidades dos estudantes com Deficiência Intelectual (DI).

Em relação ao professor especialista, observou-se que a unidade escolar dispõe de 3 professoras especialistas na área de DI, também conforme previsto tanto na política nacional quanto na resolução estadual. A partir dessas constatações, iniciou-se o olhar sobre como o APE é realizado nesse contexto, o que aconteceu apenas com uma das professoras da SR, uma vez que essa autorizou e aceitou participar da pesquisa em questão.

O APE ocorria sempre conforme o previsto em lei no que tange à avaliação, acompanhamento e desenvolvimento dos estudantes PAEE. No entanto, havia implicações da própria realidade observada que necessita algumas reflexões, dado que essas implicações são fundamentais para a inclusão dos estudantes PAEE e, sendo assim, para um efetivo ensino colaborativo.

Como apresentado no item 2 desse artigo, tanto o AEE, quanto o APE devem ocorrer no contra turno em que o estudante está na sala comum, ou seja, compreende-se que não se deve retirar nenhum estudante da sala de aula comum para a SR. Esse fato é importante, pois, pela própria definição, o AEE e APE se caracterizam como serviço de apoio, complementando ou suplementando o ensino regular. Sendo assim, pelos princípios da educação inclusiva, não faz sentido retirar da sala de aula comum o estudante PAEE.

No entanto, alguns estudantes não eram atendidos conforme a indicação das políticas públicas. Este fato é resultante das especificidades dos horários disponíveis dos atendimentos, considerando que os estudantes observados iniciaram os atendimentos apenas no segundo semestre do ano letivo e não tinham disponibilidade de tempo no contra turno, seja por falta de um responsável para o acompanhamento à escola, ou por fazerem parte de outros projetos escolares e sociais.

Assim, os estudantes observados sempre eram retirados da sala de aula comum para terem o seu atendimento realizado. É necessário que as estudantes recebam atendimento especializado de forma a não comprometer suas atividades na sala de aula comum, sendo assim, cabe destacar que não é o intuito do APE substituir as atividades da sala comum. Pautando-se nos princípios da Educação Especial em uma perspectiva inclusiva, o atendimento 
especializado substituindo o ensino realizado na sala de aula comum acarreta em muitos problemas, sendo o primeiro deles um retrocesso ao modelo de educação especial integracionista.

Nesse sentido, há a preocupação em relação à forma como a inclusão dos estudantes PAEE está ocorrendo na escola comum, pois sem a efetivação dos serviços da educação especial como previsto nas políticas públicas, estará ocorrendo a exclusão dos estudantes PAEE mesmo estes estando na escola regular, ou seja, estarão apenas inseridos. Com isso, as características e limitações deste público serão evidenciadas, ao invés de serem desenvolvidas e potencializadas para uma aprendizagem significativa.

Conforme os estudantes são retirados da sala de aula para terem outro tipo de atendimento, evidencia-se um caráter não inclusivo, com características de um modelo pautado na integração desses estudantes, devido à exclusão dos processos de ensino e aprendizagem. Assim, ressalta-se que o atendimento especializado deveria servir como complemento às atividades da sala comum.

Nesse direcionamento, concorda-se com Rodrigues (2006, p. 4) quanto à superação do modelo de escola integrativa, ainda presente nas escolas regulares, mesmo essa remetendo ao discurso de uma educação inclusiva:

Assim, quando se fala de escola Integrativa trata-se de uma escola que em tudo semelhante a uma escola tradicional em que os alunos com deficiência (os alunos com outros tipos de dificuldades eram ignorados) recebiam um tratamento especial. A perspectiva da EI é sim bem oposta à da escola tradicional e integrativa ao promover uma escola de sucesso para todos ao encarar os alunos como todos diferentes e necessitados de uma pedagogia diferenciada (PERRENOUD, 1996) e cumprindo o direito à plena participação de todos os alunos na escola regular.

Não adianta termos apenas os serviços a serem prestados, as diretrizes a serem cumpridas e as especificidades de um trabalho em parceria para um bem comum, que é a aprendizagem de todos. Mas, tem-se que superar os modelos que segregam e integram, para um modelo que inclui, que considera e trabalha com as diferenças presentes no ambiente escolar. Considera-se que essa superação seria possível a partir do ensino colaborativo.

A educação inclusiva se configura como um processo, com desafios e avanços que envolvem todos os membros da comunidade escolar. Nesse sentido, o ensino colaborativo pode proporcionar os caminhos para uma escola inclusiva.

Portanto, a partir dessas reflexões e desses pontos observados, levou-se a acreditar que a proposta de um ensino colaborativo deve de fato se concretizar nas escolas regulares. As diretrizes apontam um trabalho de apoio, articulado entre os profissionais da educação, mas há problemas e desafios a serem enfrentados, pois cada realidade possui suas especificidades e, com isso a colaboração e parcerias podem favorecer um novo quadro para a educação especial numa perspectiva inclusiva. 


\subsection{Práticas Pedagógicas: sala comum $x$ sala de recursos}

De pronto cabe destacar a ausência de parcerias nas práticas pedagógicas presentes no contexto observado e tão pouco desenvolvimento e construção colaborativa, ou seja, não havia uma articulação entre essas professoras. O que ocorria era a troca de informações gerais sobre os estudantes e algumas orientações direcionadas por parte da professora especialista, junto a coordenadora pedagógica, para os professores da sala comum de forma geral.

Essa realidade apresentava um quadro bastante frequente, existente nas escolas comuns, que é o fato da Educação Especial e do ensino regular ainda não se "misturar", ou seja, não há efetiva participação e apoio pedagógico consistente entre os professores da sala comum e da Educação Especial, e a gestão no espaço escolar. O apoio ou a articulação ocorre timidamente, ou de forma bastante generalizada e isolada, sem resultados significativos que configurem um modelo de ensino colaborativo e a articulação dos profissionais.

Um dos motivos que certamente pode ser apontado como causa dessa falta de articulação são as próprias condições de trabalho dos professores envolvidos. A carga horária de trabalho era um dos empecilhos, o que fazia com que pouco se encontrassem na escola, aumentando as demandas de cada um e reduzindo o tempo para planejamento e maior dedicação às atividades escolares.

Trata-se de um problema que possui caráter estrutural e inicia-se na formação de cada profissional, o que certamente acarreta problemas na atuação profissional docente, desde os professores da sala comum, quanto os professores da Educação Especial. Além disso, pode-se citar a quantidade de estudantes por sala de aula, as condições adversas de trabalho, cargas horárias excessivas para contemplar a má remuneração e, principalmente, a falta de orientação e apoio dos sistemas de ensino como grandes entraves à educação inclusiva.

Foi observado que a professora da sala comum não sabia a forma adequada de se trabalhar com as estudantes com DI na sala de aula e, com isso, em suas aulas eram planejadas sem considerar as especificidades das estudantes com DI, considerando assim, que todos aprendiam da mesma forma. Sempre que possível a professora da sala comum fazia orientações individual para as estudantes com DI, mas não se observou práticas e estratégias de ensino que pudessem contemplar a todos.

Assim, os fatos observados levam a concluir que, de fato, não havia um trabalho articulado entre as professoras como as políticas públicas direcionam e nem mesmo nuances de um ensino colaborativo. É necessário, portanto, desmistificar o fato do estudante PAEE ser um problema da Educação Especial e se pensar em estratégias a serem desenvolvidas sob o olhar do ensino colaborativo. Há a extrema necessidade de a Educação Especial prestar os seus serviços ao ensino regular, mas esses devem ser prestados de forma colaborativa, considerando o contexto da escola regular, professores, gestores, funcionários, a comunidade e todos os estudantes.

Por isso, é necessário não só pensar nos princípios do ensino colaborativo a fim de articular todos os setores do ambiente escolar para um bem comum, como também buscar metodologias condizentes a isso. Não se pode apenas atribuir ações aos professores e gestores, 
é necessário ter meios viáveis e contextualizados para isso. A seguir, são apresentadas reflexões sobre o ensino colaborativo, geradas a partir das percepções do contexto observado e da concepção do uso das Tecnologias por meio de uma abordagem que potencializa a inclusão e colaboração.

\subsection{O uso das tecnologias: reflexões sobre a abordagem construcionista contextualizada e significativa (ccs) visando um ensino inclusivo}

O uso das Tecnologias Digitais de Informação e Comunicação (TDIC) no processo de ensino e aprendizagem para os estudantes da Educação Especial proporciona um espaço mais inclusivo e colaborativo. Isso ocorre se considerar o uso do computador e de diversas outras tecnologias numa perspectiva contextualizada e significativa para todos os estudantes.

No que tange a colaboração na concepção apresentada nesse artigo, o uso das TDIC se torna ainda mais viável, uma vez que, recursos tecnológicos podem ser elaborados em parceria e desenvolvidos e aplicados tanto com a professora especializada em Educação Especial nas SR quanto para os professores da Sala comum, o que torna a prática dos mesmos mais diversificada e atrativa. Sendo assim, apresenta-se uma abordagem metodológica que utiliza as tecnologias de forma a potencializar um ensino inclusivo e colaborativo.

A abordagem Construcionista Contextualizada e Significativa (CCS), segundo Schlünzen (2015) é construcionista porque utiliza de estratégias pedagógicas e tecnologias que possibilitam a construção do conhecimento, a partir de objetos palpáveis, ou seja, de objetos criados pelos próprios estudantes.

Nesta concepção construcionista as práticas de ensino se tornam mais inclusivas, uma vez que, é possível trabalhar de forma colaborativa, pois, é papel do professor especialista confeccionar materiais e produtos de acordo com as necessidades dos seus estudantes. Assim, na vertente construcionista o ensino colaborativo seria potencializado e essencial na promoção e execução de recursos e materiais que partam das necessidades e dos contextos dos estudantes. Cabe destacar que a parceria e corresponsabilidade na vertente construcionista é primordial para um ensino inclusivo na sala de aula comum.

A abordagem é contextualizada porque tudo o que é construído emerge do próprio contexto dos estudantes, onde as atividades escolares são realizadas a partir do contexto real da sala de aula. Nessa vertente contextualizada, a colaboração conforme já apresentado nesse artigo se faz necessária e se potencializa de modo a considerar que ambos os professores possuem condições para planejar e desenvolver estratégias e recursos de modo a considerar o contexto de todos. Sendo assim, as práticas seriam colaborativas desde do planejamento à execução e avaliação do processo, deixando claro que a responsabilidade do PAEE é também do professor da sala de aula comum.

A abordagem CCS possui sua dimensão significativa, uma vez que, os estudantes constroem o conhecimento a partir de um contexto que eles mesmos estão inseridos e, assim, vão atribuindo significado aos conceitos que estão envolvidos no processo de ensino e aprendizagem. 
Com a abordagem CCS, se torna possível uma transformação na prática pedagógica do professor, uma vez que, há mudança de posturas e atitudes que requer a interdisciplinaridade para a mediação da aprendizagem de todos os estudantes.

Portanto com a abordagem CCS pode se desenvolver melhor o ensino colaborativo e principalmente potencializar práticas mais eficazes no contexto das salas de aula comum e das Salas de Recursos devido ao fato de que pode propiciar a resolução de problemas que nascem em sala de aula e cujos estudantes, juntamente com o professor, decidem desenvolver, um projeto que faz parte da vivencia e do contexto dos mesmos.

\subsection{Ensino Colaborativo: percepções e reflexões do contexto}

A partir das considerações anteriores, a consolidação do ensino colaborativo é necessária e possível, mas desde que, de acordo com Argueles, Huhes e Schumm (2000), haja tempo para um planejamento comum das atividades e dos objetivos que serão ensinados aos estudantes PAEE, além do suporte necessário que esses professores devem receber da gestão escolar em apoio à efetivação da parceria colaborativa.

No que tange às dificuldades encontradas em relação à prática pedagógica na sala de aula comum, pode-se dizer que o ensino colaborativo proveria melhores condições e preparo para a professora participante da pesquisa, uma vez que a parceria estabelecida a orientaria para os desafios de contemplar o currículo ao estudante PAEE, pois conforme Machado e Almeida (2010, p. 345) o ensino colaborativo deve "criar opções para aprender e prover apoio a todos os estudantes em sala de aula de ensino regular, combinando as habilidades do professor comum e do professor especialista".

Para tanto, é necessário compreender que a educação inclusiva requer práticas pedagógicas que superem as práticas tradicionais de ensino, não que estas devem ser desconsideradas, mas há que identificar no contexto as possibilidades de mediação pedagógica para um processo de ensino e aprendizagem significativo. Por isso, acredita-se no ensino colaborativo como uma importante consolidação de um ensino inclusivo, pois este deve trabalhar com uma abordagem metodológica inovadora e que considere as diferenças e níveis de aprendizagem presentes na sala de aula comum.

Um ponto de destaque que deve ser dado para essas reflexões é o fato das próprias professoras participantes da pesquisa terem relatado a importância e ajuda que teriam se houvesse um elo entre elas, ou seja, um agente mediador que pudesse facilitar o processo de um ensino colaborativo. Esse fato, vale ressalvas, uma vez que, diante dos problemas enfrentados no que tangem às concepções de ensino colaborativo e às especificidades presentes no contexto observado, um profissional que agisse em prol dessa efetiva articulação propiciaria um processo significativo de inclusão, acompanhamento, desenvolvimento e aprendizagem para o estudante PAEE, assim como efetivaria melhorias nas práticas dos professores, repensando estratégias de ensino para um currículo centrado nas habilidades e potencialidades de todos os estudantes.

Outra reflexão é em relação às metodologias de ensino que podem possibilitar o ensino colaborativo, ou seja, formas simples que podem considerar um mesmo currículo para todos, 
fazendo com que o professor da sala comum trabalhe com o professor especialista e ambos partilhem de conhecimentos emergidos do contexto, visando um trabalho pedagógico inclusivo tanto na sala de aula comum, quanto nas especificidades da SR. Nesse direcionamento, a pesquisa de Mestrado optou pela abordagem CCS apresentada anteriormente.

Reflete-se sobre o importante papel que o professor coordenador do núcleo pedagógico da Educação Especial, em parceria com os professores coordenadores das demais áreas do conhecimento, poderia ter nesse processo. Esses profissionais poderiam realizar um trabalho mais efetivo nas escolas comuns, externo às Diretorias de Ensino, propondo encontros de formação para que a construção colaborativa de fato ocorresse, além do apoio e orientação que ações como essas possibilitam para os professores.

Há também que se pensar no papel da própria gestão de cada unidade escolar, repensando a inclusão do estudante PAEE desde da matrícula até a sala de aula. Sendo assim, deve-se pensar, em ações que envolvem toda a comunidade escolar, articulando os setores educacionais com as ações dos professores, em constante processo de melhorias na qualidade de ensino.

Por fim, é importante ressaltar que o objetivo desse artigo foi o de refletir sobre as nuances do ensino colaborativo nas políticas públicas em especial a Política Nacional da Educação Especial na perspectiva da Educação Inclusiva, e algumas vertentes da resolução do Estado de São Paulo. Para isso, foi apresentado alguns elementos de uma realidade observada no decorrer de uma pesquisa de Mestrado. Não há a intenção nesse artigo de apresentar modelos de como poderia ocorrer um ensino colaborativo, mas houve a intenção de levantar reflexões e questionamentos de realidades e de possibilidades para que se efetive colaboração. A pesquisa em sua fase de conclusão apresentará uma intervenção e proporcionará contribuições significativas de como poderia ocorrer colaboração em diversos contextos escolares entre a Educação Especial e Ensino Regular.

\section{Considerações Finais}

Em relação às políticas públicas destacadas, pode-se afirmar que configuram nos últimos anos importantes tomadas de decisões e efetivações dos serviços da Educação Especial, em termos de recursos disponibilizados e salas de recursos ofertadas em todo o território brasileiro, assim como, o crescente número de professores especializados que se formaram ao longo desse processo.

No entanto, não se pode afirmar sobre a consistência das políticas públicas no que se refere ao caráter complementar e colaborativo entre o trabalho pedagógico da Educação Especial com o ensino regular. Isso ficou evidente, dado as poucas e interpretativas diretrizes trazidas pela política nacional e estadual, uma vez que as mesmas também não pontuam a forma sobre como poderia ocorrer espaços de apoio, parcerias e articulação, o que fragiliza o processo inclusivo. Por isso, evidenciou-se a necessidade da efetivação de políticas públicas que considerem e direcionem de forma mais consistente uma forma de ensino colaborativo para uma escola inclusiva, principalmente trazendo respaldo para os professores. 
No que diz respeito ao contexto observado, foi possível nesta breve explanação evidenciar alguns pontos que merecem destaque: é necessário considerar contextos reais para se pensar em políticas públicas; é fundamental compreender o conceito de educação inclusiva e se pautar nos princípios de ensino colaborativo para que a Educação Especial caminhe junto com o ensino regular; é importante destacar a urgência nas melhorias da qualidade de ensino, desde da sua estrutura, até configurar um quadro de extrema valorização docente em todo país, não é mais tolerável que professores da rede pública estadual trabalhem sob tamanhas condições adversas e sem a valorização pelo o que Ihe é atribuído; é considerável propor o elo entre a Educação Especial e classe comum, como apontado pelas professoras participantes da pesquisa, mas desde que esse profissional tenha a clareza de suas atribuições e que não seja mais um agente de ensino que trabalhe de forma desarticulada; é imprescindível que se busque metodologias de ensino centradas em um novo fazer pedagógico, que considere as diferenças. Não se pode mais robotizar a educação.

No que tange a abordagem CCS e o uso das TDIC acredita-se que a melhor maneira de articular a abordagem CCS em situações reais de aprendizagem, seja por meio de práticas colaborativas entre a Educação Especial e Inclusiva, uma vez que, permitem uma abordagem interdisciplinar, favorecem a atribuição de significados ao que está se aprendendo, pois contextualiza de maneira significativa elementos do cotidiano e do senso comum a conceitos científicos das diversas disciplinas, que não devem ser fragmentadas e estanques.

Portanto, concorda-se que há um longo percurso a ser conquistado, há desafios a serem superados, problemas a serem resolvidos, mas também se reconhece que há mudanças acontecendo, existem programas de formação que tem se atentado a essas questões e recursos sendo desenvolvidos e utilizados na escola básica. Mas, percebe-se a importante urgência das questões levantadas, considerando que as políticas públicas compõem um fator determinante de ações tomadas pelas instituições de ensino. Desse modo, acredita-se na valorização daquilo que já se sabe, já está dando certo, porém é necessário avançar para uma educação de qualidade para todos.

\section{Referências}

ARgUeleS, M. E., HUGHES, M. T., SCHUMM, J. S. Co-teaching: a Different Aproach to inclusion. Principal (Reston, Va) 79 n. 4 48, 50-1 Mr. 2000.

BAPTISTA, Cláudio Roberto. Ação pedagógica e educação especial: a sala de recursos como prioridade na oferta de serviços especializados. Revista Brasileira de Educação Especial, v. 17, p. 59-76, Marília, 2011.

BOGDAN, R.; BIKLEN, S. Investigação qualitativa em educação: uma introdução à teoria e aos métodos. Porto: Porto editora, 1994. 336 p.

BRASIL. Ministério da Educação. Secretaria de Educação Especial. Política Nacional de Educação Especial na perspectiva da educação inclusiva. Brasília, DF, 2008.

Decreto no 6.571, de 17 de setembro de 2008.

COOK, L \& FRIEND, M. Co-teaching: Guidelines for creating effective practices. Focus on Exceptional Children, no 28, pp, 1-16, 1995. 
CONDERMAN, G.; BRESNAHAN, V; PEDERSEN, T. Purposeful co-teaching: real cases and effectives strategies. Thousand Oaks: Corwin Press, 2009a.

FERREIRA, B.C., Mendes, E.G., Almeida, M.A., \& Del Prette, Z.A.P. Parceria colaborativa: Descrição de uma experiência entre o ensino regular e especial. Revista Educação Especial (UFSM), 29, p. 9-22, 2007.

MACHADO, A. C.; ALMEIDA, M. A. A.. Parceria no contexto escolar: uma experiência de ensino colaborativo para educação inclusiva. Rev. Psicopedagogia, v. 27, n. 84, 2010, p. 344-351.

MENDES, E. Colaboração entre ensino regular e especial: o caminho do desenvolvimento pessoal para a inclusão escolar. In: MANZINI, E. J. Inclusão e acessibilidade. Marília, 2006. p. 29-41.

MENDES, E. G., ALMEIDA, M. A., TOYODA, C. Y. Inclusão escolar pela via da colaboração entre educação especial e educação regular. Curitiba, n. 41, p. 81-93, jul./set. 2011.

MENDES, E.G; VILARONGA, C.A.R; ZERBATO, A.P. Ensino Colaborativo como Apoio à Inclusão Escolar: Unindo esforços entre a educação comum e especial. São Carlos: EdUFSCar, 2014. 160 p.

MICHELS, M. H.. Paradoxo da formação docente na política de educação inclusiva de Estado de Santa Catarina: a perspectiva clinica como sustentação do trabalho escolar. In.: BAPTISTA, C. R.; JESUS, D. M. (orgs.). Avanços em políticas de inclusão: o texto da educação especial no Brasil e em outros países. Porto Alegre: Mediação, 2009, p. 139-152.

PRIETO, R. G. Políticas de inclusão escolar no Brasil: sobre novos/velhos significados para a educação especial. In.: MENDES, E.; ALMEIDA, M. A. (orgs.). Das margens ao centro: perspectivas para as políticas e práticas educacionais no contexto da educação especial. Araraquara/SP: Junqueira\&Marin, 2010, p. 61- 78.

PUGACH, M.; JOHNSON, L. Collaborative practitioners, collaborative schools. Denver: Love Publishing, 1995

RODRIGUES, D. (2006). Dez ideias (mal) feitas sobre a Educação Inclusiva. In David Rodrigues (org.) Inclusão e Educação: Doze olhares sobre a Educação Inclusiva. São Paulo: Summus Editorial.

São Paulo (Estado). Resolução SE no 11, de 31 de Janeiro de 2008.

Resolução SE no 31, de 24 de Março de 2008.

Resolução SE nº 61, de 11 de Novembro de 2014.

Submetido para avaliação em 05 de abril de 2016

Aprovado para publicação em 10 de outubro de 2016

\section{Naiara Chierici da Rocha}

Mestre em Educação - Faculdade de Ciências e Tecnologia - FCT/UNESP, Brasil, anaknaul@gmail.com

Elisa Tomoe Moriya Schlünzen

Professora Dra. Faculdade de Ciências e Tecnologia - FCT/UNESP, Brasil, dadaniela@gmail.com

\section{Danielle A. Nascimento dos Santos}

Professora Dra. Universidade do Oeste Paulista - UNOESTE, Brasil, anaknaul@gmail.com 